\title{
Esophageal involvement in Wegener's granulomatosis: A case report and review of the literature
}

Glen A Fallows MD, Sean F Hamilton MD FRCPC, Douglas S Taylor MD FRCPC, S Bharati Reddy MD FRCPC

GA Fallows, SF Hamilton, DS Taylor, SB Reddy. Esophageal involvement in Wegener's granulomatosis: A case report and review of the literature. Can J Gastroenterol 2000:14(5):449. 451. Wegener's granulomatosis is characterized by a granulomatous arteritis involving the upper and lower respiratory tracts, progressive glomerulonephritis and systemic symptoms attributable to small vessel vasculitis. Although multisystemic manifestations are frequent, involvement of the gastrointestinal tract is uncommon. Cases have been reported of intestinal perforation, ulceration and hemorrhage. A patient whose initial presentation of Wegener's granulomatosis was odynophagia secondary to esophageal vasculitis is described. Endoscopy revealed multiple punched out ulcerations in the esophagus, which resolved with standard therapy for systemic Wegener's granulomatosis. There are only two previous reports of symptomatic esophageal vasculitis in patients with Wegener's granulomatosis. These reports illustrate the need to consider odynophagia as a reflection of disease activity as opposed to complications of immunosuppressive therapy.

Key Words: Esophagus; Vasculitis; Wegener's granulomatosis

\section{Granulomatose de Wegener et atteinte de l'œsophage : exposé de cas et survol de la documentation scientifique}

RÉSUMÉ : La granulomatose de Wegener se caractérise par une artérite granulomateuse des voies respiratoires supérieures et inférieures, une glomérulonéphrite progressive et des symptômes généraux attribuables à une angéite nécrosante des petits vaisseaux. Bien que la maladie touche plusieurs systèmes, il est rare que le tube digestif soit atteint. On a déjà fait état de perforation de l'intestin, d'ulcères et d'hémorragies. Voici le cas d'un patient ayant comme première manifestation de la granulomatose de Wegener une odynophagie secondaire à une vascularite oesophagienne. L'endoscopie a révélé la présence de nombreuses perforations ulcéreuses dans l'œsophage, qui ont cédé au traitement classique de la granulomatose de Wegener généralisée. Seuls deux cas de vascularite oesophagienne symptomatique chez des patients atteints de granulomatose de Wegener ont déjà été signalés. Les rapports illustrent la nécessité de considérer l'odynophagie comme le reflet d'une activité pathologique plutôt que comme une complication d'un traitement immunosuppresseur.
W egener's granulomatosis is characterized by agranulomatous arteritis involving the upper and lower respiratory tracts, progressive glomerulonephritis and systemic symptoms attributable to small vessel vasculitis. Although multisystemic manifestations are frequent, involvement of the gastrointestinal tract is uncommon. A patient whose initial presentation of Wegener's granulomatosis was odynophagia secondary to esophageal vasculitis is described. Standard therapy for systemic Wegener's granulomatosis resulted in resolution of the gastrointestinal complications.

\section{CASE PRESENTATION}

A 34-year-old female presented to hospital with a four-day history of severe odynophagia for solids and liquids, with inability to eat due to pain. She also had developed ischemic lesions in her feet and fingers, palpable petechiae on both forearms, dry cough, bilateral scleral injection and arthralgias of the fingers, wrists and ankles. In the four weeks before presentation, she was treated for otitis media after developing decreased hearing acuity in the left ear. She subsequently developed purulent drainage from the ear and was 


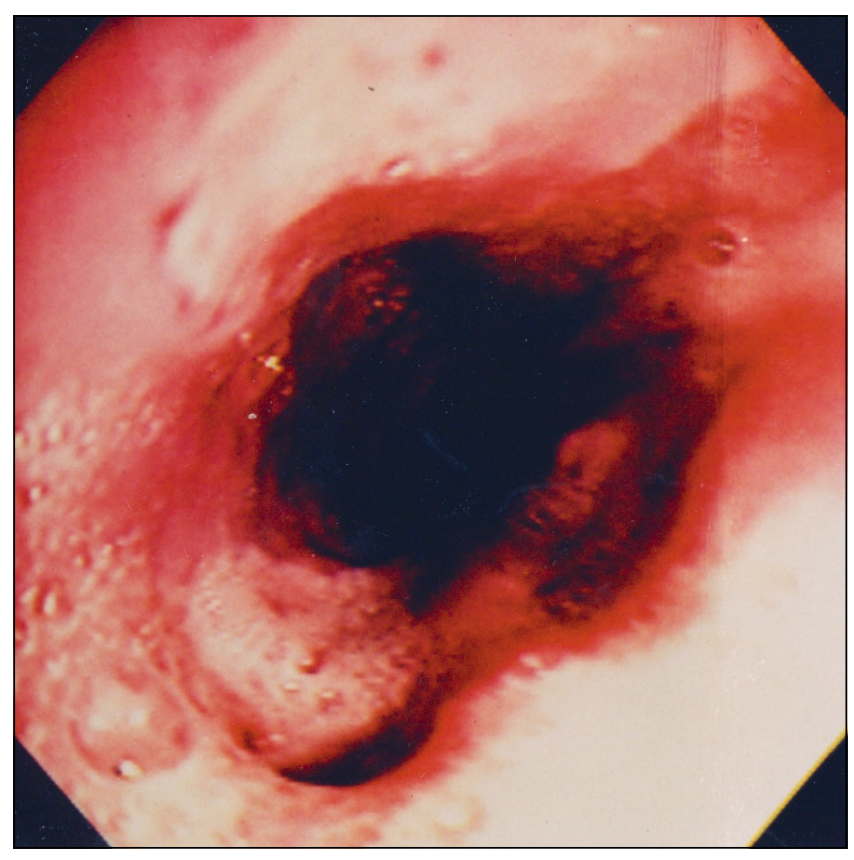

Figure 1) Esophagoscopy showing punched out ulcerations extending from $20 \mathrm{~cm}$ to the esophagogastric junction

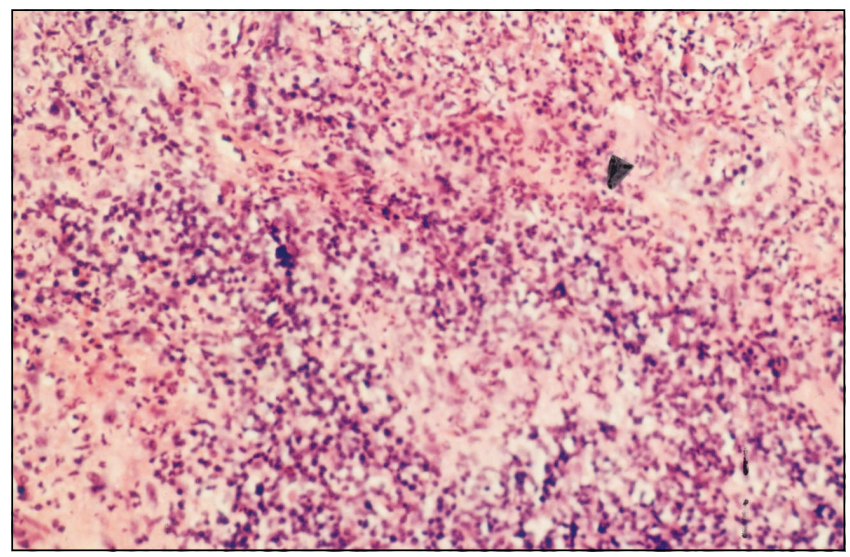

Figure 2) Photomicrograph of an esophageal biopsy showing fibrinoid necrosis, ulceration and inflammatory cell infiltration surrounding small vessels consistent with a vasculitic process

treated with a week of trimethoprim/sulphamethoxazole. This was followed by a week of treatment with amoxicillin after the patient failed to respond to the initial course of antibiotics.

Her past medical history was insignificant apart from a donor nephrectomy; she had donated a kidney to her brother. There was no previous history of odynophagia, peptic ulcer disease or reflux symptoms. Medications included diclofenac as needed for her arthralgias in addition to the above mentioned antibiotics. She denied alcohol intake and smoked one pack/day for 12 years.

On examination, she looked unwell, but was hemodynamically stable and afebrile. There were multiple 1 to $2 \mathrm{~mm}$ white ulcers in her posterior oropharynx as well as many $1 \mathrm{~mm}$ ulcers and petechial lesions in both nares. The left

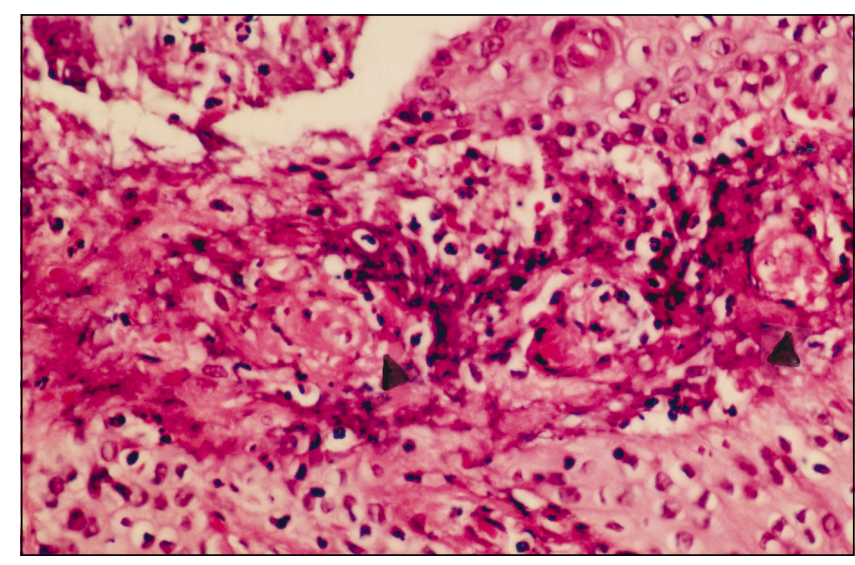

Figure 3) Photomicrograph of a skin biopsy showing fibrinoid degradation of small arteries with acute inflammatory cell infiltration

tympanic membrane was erythematous, and she had bilateral conjunctivitis. There were numerous raised petechial lesions on both forearms as well as ischemic areas located on her right fifth toe and first metatarsophalangeal joint. Joint effusions were noted in her right second, third and fifth metacarpophalangeal joints, right wrist and first and fifth metatarsophalangeal joints.

Initial laboratory studies revealed a white blood cell count of $10.7 \times 10^{9} / \mathrm{L}\left(4.4\right.$ to $\left.11.0 \times 10^{9} / \mathrm{L}\right)$, hemoglobin level of $111 \mathrm{~g} / \mathrm{L}$ (normocytic, normochromic) and platelet level of $599 \times 10^{9} /$ L. Electrolytes and liver enzyme levels were normal and her creatinine level was $98 \mu \mathrm{mol} / \mathrm{L}$. The erythrocyte sedimentation rate was $125 \mathrm{~mm} / \mathrm{h}$. Urinalysis showed many red blood cells with no white blood cells or casts, and proteinuria of $0.27 \mathrm{~g} /$ day. Her estimated creatinine clearance was $70 \mathrm{~mL} / \mathrm{min}$.

Esophagogastroduodenoscopy two days after admission revealed multiple discrete and punched out ulcers starting at $20 \mathrm{~cm}$ and extending to the esophagogastric junction (Figure 1). The ulcers were atypical for ulcerative esophagitis and appeared vasculitic in nature. Because of the endoscopic findings, prednisone therapy was initiated. Within $24 \mathrm{~h}$, improvement was noted in her gastrointestinal symptoms, as well as the ulcerations in the nose and oropharynx. Esophageal biopsies revealed fibrinoid necrosis with ulceration and inflammatory cell infiltration surrounding small vessels, in keeping with a vasculitic process (Figure 2). Biopsy of a skin lesion showed fibrinoid degradation of small arteries with acute inflammatory cell infiltration (Figure 3). Granulomata were not noted in either biopsy.

Further laboratory studies revealed negative tests for antinuclear antibody, cryoglobulins, cold agglutinins and hepatitis $\mathrm{B}$ surface antigen. $\mathrm{C}_{3}$ and $\mathrm{C}_{4}$ levels were normal, and rheumatoid factor was positive at $32 \mathrm{U} / \mathrm{mL}$. Measurement of cytoplasmic antinuclear antibody (c-ANCA) was positive at a titre of 1:160.

Wegener's granulomatosis was diagnosed on the basis of ear, nose and throat involvement (otitis media, nasal and oral ulcerations), kidney involvement (hematuria, proteinuria and renal insufficiency), positive c-ANCA and biopsies 
consistent with a small vessel vasculitis. Treatment was initiated with cyclophosphamide $100 \mathrm{mg}$ once daily and prednisone $60 \mathrm{mg}$ once daily. This resulted in resolution of the ischemic areas and vasculitic lesions on her arms, fingers and feet. Her renal function stabilized and fell to 20 .

\section{DISCUSSION}

Systemic vasculitis is generally believed to be an immune complex deposition in blood vessels. Gastrointestinal complications of vasculitis have been described as pain, diarrhea, rectal bleeding and abnormal liver enzymes (1). Taken in isolation, the symptoms are difficult to distinguish from inflammatory bowel disease, infectious colitis or ischemic colitis, although gastrointestinal vasculitis rarely presents without other clinical evidence of systemic vasculitis. Histological proof is difficult to obtain because biopsies from the gastrointestinal tract usually show only nonspecific inflammation and ulceration. Camilleri and Pusey (1) suggested that this may be because endoscopic biopsies are too superficial and proposed that endoscopic examination was the best method to determine extent of disease. Diagnosis is often made clinically from the involvement of other organ systems because biopsies frequently show no evidence of a specific vasculitis. Therapy is aimed at treating the systemic vasculitis with immunosuppressive medications and with surgical intervention in the event of gastrointestinal complications such as hemorrhage or perforation.

Vasculitic involvement of the gastrointestinal tract is more common in polyarteritis nodosa and microscopic polyarteritis (50\% to $70 \%$ ) and Chrug-Strauss syndrome $(20 \%)$ than in Wegener's granulomatosis (1). Walton (2) published autopsy studies of patients with Wegener's granulomatosis and found gastrointestinal involvement in 24\%, although none of these patients had symptoms referable to the gastrointestinal tract. Two large groups of patients with Wegener's granulomatosis have been followed for over 20 years $(3,4)$, and neither study describes gastrointestinal complications throughout the course of the disease. Case reports of

\section{REFERENCES}

1. Camilleri M, Pusey CD. Gastrointestinal manifestations of systemic vasculitis. Q J Med 1983;206:141-9.

2. Walton EW. Giant-cell granuloma of respiratory tract. BMJ 1958;2:265-70.

3. Fauci AS, Haynes BF, Katz P, et al. Wegener's granulomatosis: Prospective clinical and therapeutic experience with 85 patients for 21 years. Ann Intern Med 1983;98:76-85.

4. Hoffmann GS, Kerr GS, Leavitt RY, et al. Wegener's granulomatosis: An analysis of 158 patients. Ann Intern Med 1992;116:488-98.

5. Kemp JA, Arora S, Fawaz K. Recurrent acute pancreatitis as a manifestation of Wegener's granulomatosis. Dig Dis Sci 1990;35:912-5.

6. Haworth SJ, Pusey CD. Severe intestinal involvement in Wegener's granulomatosis. Gut 1984;25:1296-300.

7. Wilson RH, McLoughlin J, Gormley M. Symptomatic colitis as the initial presentation of Wegener's granulomatosis. Br J Clin Pract 1993;47:315-8.

8. Tupler RH, McCuskey WH. Wegener's granulomatosis of the colon: CT and histologic correlation. J Comput Assist Tomogr 1991;15:314-6.

9. Sokol RJ, Farrell MK, McAdams AJ. An unusual presentation of Wegener's granulomatosis mimicking inflammatory bowel disease. Gastroenterology 1984;87:426-32.

10. Uribe A, Goobar J, Rubio C. Colonic ulcerations in Wegener's granulomatosis. J Rheumatol 1991;18:1429-30.

11. Wilson RT, Dean PJ, Upshaw JD, et al. Endoscopic appearance of Wegener's granulomatosis involving the colon. Gastrointest Endosc 1987;33:388-9. gastrointestinal involvement in Wegener's granulomatosis have described cases of enterocolitis, gastrointestinal hemorrhage, intestinal perforation and recurrent pancreatitis (5).

Enterocolitis has presented as bloody diarrhea and abdominal pain, with endoscopic evaluation revealing superficial ulcerations in both the small and large intestines (6-13). The differentiation between inflammatory bowel disease rested on biopsy evidence as well as extraintestinal symptomatology. Several reports have been made of gastrointestinal hemorrhage due to ulcers in the ileum, jejunum and colon, $(14,15)$ as well as perforations of the small and large bowel (16-18). Questions have been raised as to whether immunosuppressive medications may exacerbate ulcerations $(17,18)$, although further improvement despite continuation of immunosuppressive therapy argues against this theory (18).

Esophageal involvement in Wegener's granulomatosis has rarely been reported. In an autopsy series of 29 cases, Fahey et al (19) found one patient with asymptomatic esophageal arteritis. Symptomatic vasculitic ulcerations of the esophagus associated with Wegener's granulomatosis have been reported in one case of upper gastrointestinal hemorrhage (20) and in a second case resulting in severe odynophagia (21). These two cases of esophageal involvement of Wegener's granulomatosis, in addition to our case, are noteworthy to gastroenterologists and rheumatologists. Esophageal symptoms in patients with Wegener's granulomatosis are frequently attributed to reflux esophagitis or infections due to immunosuppressive medications. The presence of esophageal symptoms in the context of a systemic vasculitis should alert the clinician to the possibility of active disease as an etiology and prompt further evaluation before initiation of antireflux or antifungal agents.

ACKNOWLEDGEMENTS: We thank Drs Vaze and Cooke in the Department of Pathology, St Clare's Mercy Hospital, St John's, Newfoundland for their assistance in interpretation of the specimens and providing photomicrographs of the pathology.

12. Davis RW, Fetter BF, Young WG Jr. Two patients presenting with solitary pulmonary lesions and review of eleven other cases. Ann Thorac Surg $1972 ; 13: 427$

13. Oddis CV, Schoolwerth AC, Abt AB. Wegener's granulomatosis with delayed pulmonary and colonic involvement. South Med J 1984;12:1589-92.

14. Coward RA, Gibbons CP, Brown CB, et al. Gastrointestinal hemorrhage complicating Wegener's granulomatosis. BMJ 1985;291:865-6.

15. Pinkney JH, Clarke G, Fairclough PD. Gastrointestinal involvement in Wegener's granulomatosis. Gastrointest Endosc 1991;37:411-2.

16. Tokuda M, Kurata N, Daikuhara H, et al. Small intestinal perforation in Wegener's granulomatosis. J Rheumatol 1989;16:547-9.

17. McNabb WR, Lennox MS, Wedzicha JA. Small intestinal perforation in Wegener's granulomatosis. Postgrad Med J 1982;58:123-5.

18. Geraghty J, Mackay IR, Smith DC. Intestinal perforation in Wegener's granulomatosis. Gut 1986;27:450-1.

19. Fahey JL, Leonard E, Churg J, et al. Wegener's granulomatosis. Am J Med 1954;17:168-79.

20. Galbraith PJ, Morgan RJ, Ferguson AD, et al. Intestinal perforation in Wegener's granulomatosis. BMJ 1985;291:1275-6. (Lett)

21. Spiera RF, Filipa DA, Bains MS, et al. Esophageal involvement in Wegener's granulomatosis. Arthritis Rheum 1994;37:1404-7. 


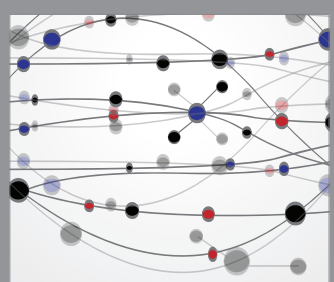

The Scientific World Journal
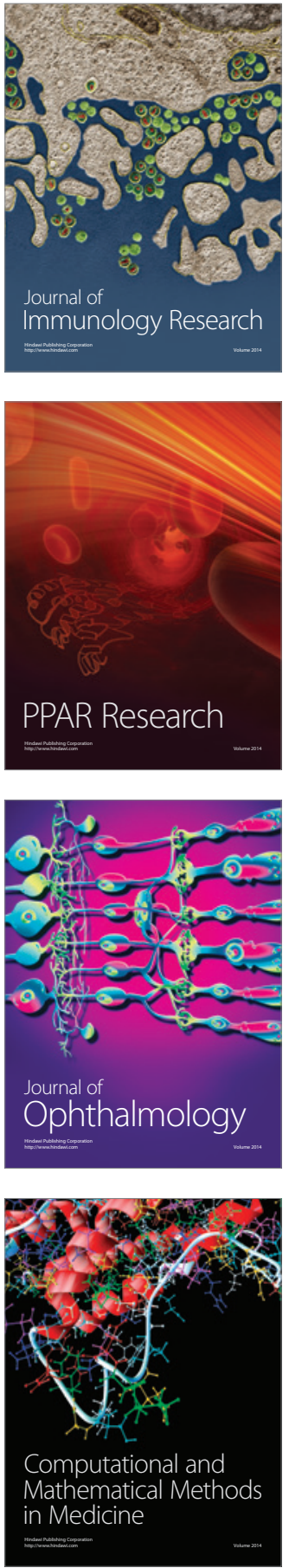

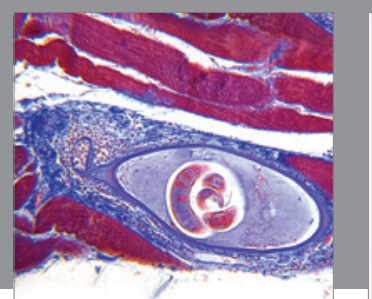

Gastroenterology Research and Practice

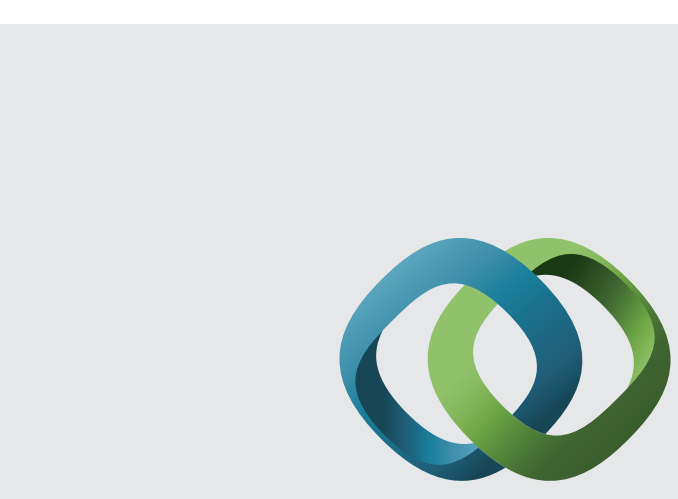

\section{Hindawi}

Submit your manuscripts at

http://www.hindawi.com
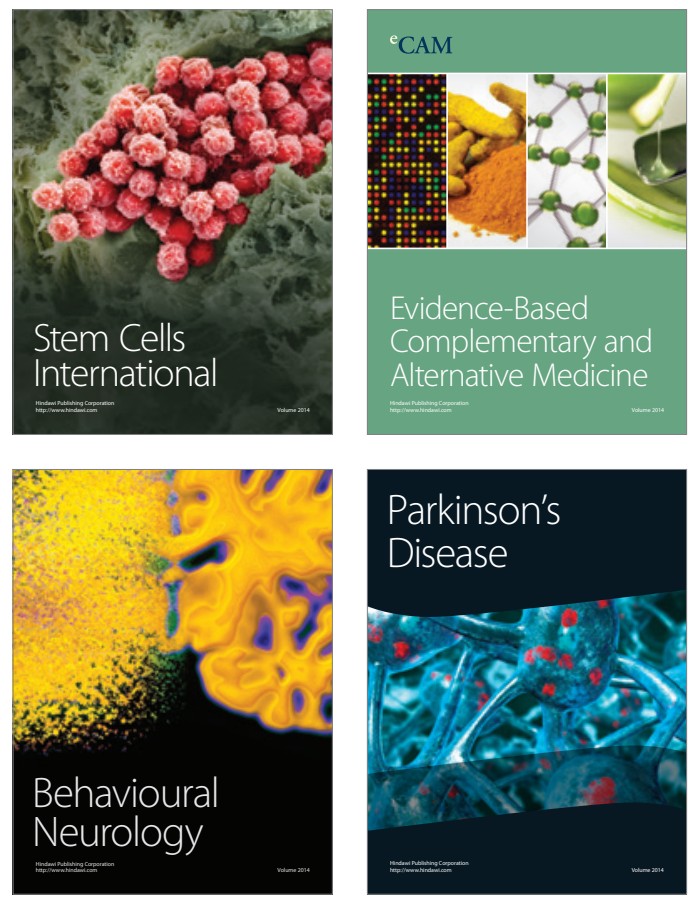
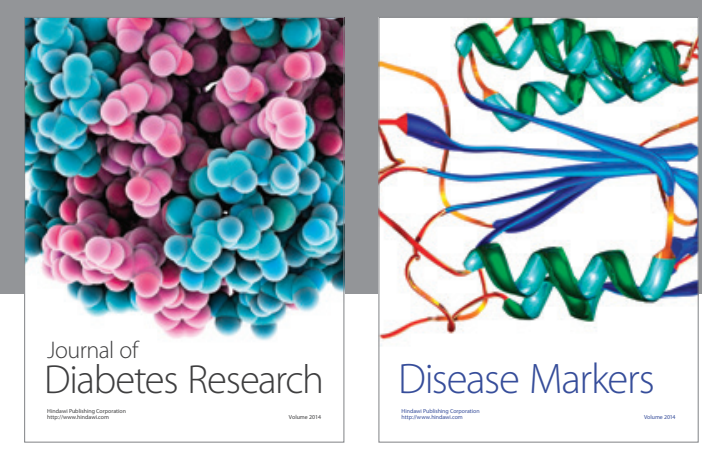

Disease Markers
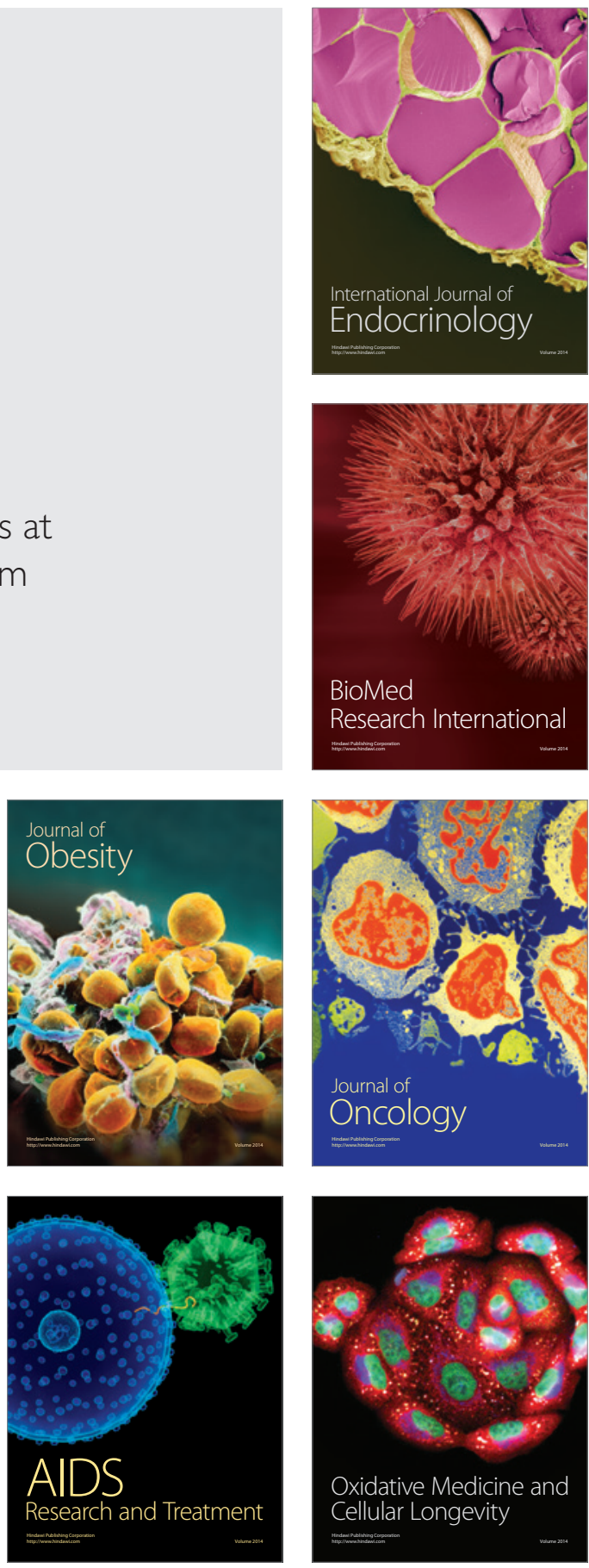